\title{
Improving the performance of a ploughing tractor by means of an auxiliary carriage with motorized axle
}

\author{
Volodymyr Bulgakov, ${ }^{1}$ Volodymyr Nadykto, ${ }^{2}$ Semjons Ivanovs, ${ }^{3}$ Ilmars Dukulis ${ }^{3}$ \\ ${ }^{1}$ National University of Life and Environmental Sciences of Ukraine, Ukraine; ${ }^{2}$ Dmytro Motornyi Tavria State \\ Agrotechnological University, Ukraine; ${ }^{3}$ Latvia University of Life Sciences and Technologies, Latvia
}

\begin{abstract}
The article describes the analysis of results from field tests on ploughing units based on a modular draft device (MDD). This device is named MDD-100 and consists of an energy module and a technological module. The energy module is a universal tractor with a rated draft resistance of $16 \mathrm{kN}$. The technological module is an additional axle, equipped with an active wheel drive, a threepoint hitch linkage, and a saddle-type semi-trailer. During the working process, the draft resistance of the energy and the technological modules of the MDD-100 add up. As a result, the draft resistance of the latter may reach $26 \mathrm{kN}$, and more. This allows the MDD-100 to be classified as a draft device in traction class 3 and be used with agricultural machines with a large working width. The MDD-100 was tested with a five-bottom mounted plough with a working width of $1.75 \mathrm{~m}$ and a draft resistance of $24-28 \mathrm{kN}$. The best option for driving the MDD-100 with a plough was its movement with the right-side wheels in the furrow. The draft resistance of the plough would decrease by $12.0 \%$, if the option of the MDD-100 outside the furrow is used. This ensured a $12.8 \%$ reduction in the skidding of the MDD-100 wheels and a $13.1 \%$ decrease of fuel consumption for the ploughing unit. Compared to a 4WD tractor, the use of a modular draft device with a 6WD wheel arrangement offered a greater stability of the ploughing depth.
\end{abstract}

\footnotetext{
Correspondence: Semjons Ivanovs, Latvia University of Life Sciences and Technologies, 2, Liela str. Jelgava, LV-2130, Latvia.

Tel.: +37129403708. E-mail: semjons@apollo.lv

Key words: Energy module; modular draft device (MDD); plough; tractor.

Conflict of interests: the authors declare no potential conflict of interests.

Received for publication: 24 July 2020.

Accepted for publication: 16 October 2020 .

(C) Copyright: the Author(s), 2021

Licensee PAGEPress, Italy

Journal of Agricultural Engineering 2021; LII:1109

doi:10.4081/jae.2021.1109

This article is distributed under the terms of the Creative Commons Attribution Noncommercial License (by-nc 4.0) which permits any noncommercial use, distribution, and reproduction in any medium, provided the original author(s) and source are credited.
}

\section{Introduction}

One way to increase the efficiency of agricultural tractors is the application of the modular principle to their construction. This principle is based on the requirements for the development of a traction-and-energy concept for a new tractor (Kutkov, 2004).

The basic essence of these requirements is that, according to this concept, the power of the tractor cannot be fully utilized when it is in traction mode. This is because this mode allows full use of the engine power only when the power saturation level (PSL) of the tractor does not exceed $15 \mathrm{~kW} \mathrm{t}^{-1}$ (Bulgakov et al., 2015).

The PSL of a tractor according to the traction-and-energy concept may be considerably greater than $15 \mathrm{~kW} \mathrm{t}^{-1}$. For instance, in the Steyr 8300 tractor, this figure reaches almost $39 \mathrm{~kW} \mathrm{t}^{-1}$ (www.tractor-db.com). Hence, the tractor based on the tractionand-energy concept contains excessive power, and, therefore requires that specific methods are developed for using it efficiently. One of these methods is to create a modular draft device (MDD).

The modular draft device, developed in Ukraine under the brand name MTD-100, consists of two modules: the energy module and the technological module (Figure 1A). The energy module (EM) is tractor MTZ-892, which has a PSL exceeding $15 \mathrm{~kW} \mathrm{t}^{-1}$. The technological module (TM) is an axle attached to the tractor with driving wheels, its own three-point hitch linkage, a saddletype semi-trailer, a brake system and its own power take-off (PTO) shaft.

The wheels of the TM are driven by the synchronous power take-off shaft of the energy module (i.e., the tractor). To ensure better ease of manoeuvrability of the MDD-100, while turning, its technological module is equipped with a vertical pivot and a horizontal pivot. The technical characteristics of the MDD-100 are reported in Table 1.

The vertical pivot ensures turning of the TM relative to the $\mathrm{EM}$ on a horizontal plane by $\pm 30^{\circ}$, while the horizontal pivot turns by $\pm 15^{\circ}$ on a transverse-vertical plane. In order to limit and dampen oscillations of the TM relative to the EM on the horizontal plane, the latter is equipped with two interconnected hydraulic cylinders in parallel. A similar design solution (a pivotal connection between the modules) was used by researchers in the self-propelled platform with an $8 \times 8$-wheel arrangement (Beloousov et al., 2013). During the working movement of the MDD-100, the main proportion of its engine power is converted into the draft resistance through the EM undercarriage system, while the remaining one is converted through the TM undercarriage system. As a result, if the traction force of the EM can reach $16 \mathrm{kN}$, then, when it is part of the TM, it can be more than $26 \mathrm{kN}$. This means that, when the energy module and the technological modules are combined, their draft resistances add up. In accordance with the Ukrainian classification of tractors, the EM refers to the traction means of the traction class 1.4. At the same time, the MDD-100 modular draft device belongs 
to the tractors with a net traction $30 \mathrm{kN}$. As a result, the MDD-100 can be combined with agricultural machines with a wider working width and made more complete consuming the extra engine power of the energy module (Pădureanu et al., 2013). The practice of using the MDD confirms that the modular principle of tractor design has a series of advantages.

Firstly, the use of the technological module as part of a modular draft device does not lead to increased soil compaction (Bulgakov et al., 2016).

Secondly, due to the technological module, the annual load of the universal tractor in the traction class 1.4 is significantly increased. Over the year, the TM may not be used, but the losses from its idle time are about 5-7 times less than the losses from the standstill of an idle tractor.

Thirdly, the probability of quality service with one operator of one brand of tractors instead of two is significantly higher.

This modular draft device is different from the conventional three-axle tractor. Although it was used in some cases across the world (Trisix Varro, Valmet 1502), no results are available in applications with ploughs. The problem is that the ploughing unit is generally asymmetric. Therefore, before attaching the plough to the draft device, one should know the required ratio between the width of its undercarriage system and the working width of the plough. Otherwise, the unfolding moment, acting upon the plough along the horizontal plane, can significantly degrade the quality of its work. Some researchers reported the negative consequences of the asymmetric attachment of a machine to the tractor (Stjelja, 2002; Simikić et al., 2012), yet they presented this machine only with reference to the strength of its resistance, which, although displaced relative to the longitudinal axis of the tractor, is directed parallel to it. In this case the design parameters of the machine are not considered (Simikić et al., 2014). Given this circumstance, research results, previously obtained by the investigators, do not

Table 1. Technical characteristics of the MDD-100.

\begin{tabular}{lcc}
\hline Parameter & Unit & Value \\
\hline Energy module & & \\
Operating mass & $\mathrm{kg}$ & 3900 \\
Engine power & $\mathrm{kW}$ & 77.2 \\
\hline Power saturation level & $\mathrm{kW} \mathrm{kg}^{-1} 10^{3}$ & 19.8 \\
Front wheel track & $\mathrm{mm}$ & 1500 \\
\hline Rear wheel track & $\mathrm{mm}$ & 1500 \\
Front wheel tire size & - & $13.6 \mathrm{R} 20$ \\
\hline Front tire inflation pressure & $\mathrm{bar}$ & 1.1 \\
Rear wheel tire size & - & $16.9 \mathrm{R} 38$ \\
\hline Front tire width & $\mathrm{mm}$ & 430 \\
Rear tire inflation pressure & $\mathrm{bar}$ & 1.3 \\
\hline Ground-speed PTO characteristic & $\mathrm{rpm}$ & 3.5 \\
\hline Technological module & & \\
\hline $\begin{array}{l}\text { Operating mass } \\
\text { Wheel track }\end{array}$ & $\mathrm{kg}$ & 2600 \\
\hline Tire size & $\mathrm{mm}$ & 1500 \\
\hline Air pressure & - & $16.9 \mathrm{R} 38$ \\
\hline MDD-100 & $\mathrm{bar}$ & 1.3 \\
\hline $\begin{array}{l}\text { Operating mass } \\
\text { Distance between the axes of the EM front } \\
\text { wheels and TM wheels }\end{array}$ & $\mathrm{mm}$ & \\
\hline
\end{tabular}

allow us to establish the required ratio between the width of the tractor undercarriage system and the working width of the plough. Moreover, they do not make it possible to assess the impact of the asymmetric attachment of the plough on the quality indicators of its work. Considering the foregoing, this article is devoted to substantiate a rational scheme for a ploughing unit based on the MDD100 from both the theoretical and experimental point of view and to assess its performance quality.

Abbreviations and symbols used in the article are listed in Table 2 .

\section{Theoretical assumptions}

It is generally assumed that all the resistance forces acting upon a plough along the horizontal plane are concentrated in a specific point, called the centre of resistance. With respect to the longitudinal axis of symmetry of the draft device (OY, Figure $1 \mathrm{~B})$, this point may be in three positions, namely: i) to the right of the specified axis at a distance $d$ (point $D_{1}$ ); ii) on the plane that passes through this axis (point $D_{o}$ ); iii) to the left of the $O Y$ axis at a distance $d$ (point $D_{2}$ ). When the centre of resistance of the plough is located at point $D_{1}$, the tractive force $T_{1}$ of the tractor, applied to the plough in the same point, can be decomposed into two components: the longitudinal $T_{1 v}$ and the transverse $T_{1} r$. The first performs useful work, as it moves the plough in the direction of the movement of the energy module. On the contrary, the second component (i.e., $T_{1 r}$ ) is not productive since it also presses the plough with its landside plates against the wall of the furrow. As a result, the force of their friction against the soil $\left(\Sigma F_{t r}\right)$ increases.

The reaction of the soil to the plough bodies can be presented by three components, namely (Figure 1B): i) the total transverse (horizontal) reaction $\left(\Sigma P_{x}\right)$; ii) the total longitudinal (vertical) reaction $\left(\Sigma P_{Y}\right)$; iii) the total normal reaction of the landside plates $\left(\Sigma F_{f}\right)$, deviated from axis $O X$ by an angle $\alpha$.

As is known,

$$
\begin{aligned}
& \Sigma F_{f} \cdot \cos \alpha=\Sigma \frac{F_{t r}}{f_{t r}} ; \\
& \Sigma F_{f} \cdot \sin \alpha=\Sigma F_{t r} ; \\
& \Sigma P_{x}=\Sigma P_{Y} \cdot \cot (\varphi+\gamma),
\end{aligned}
$$

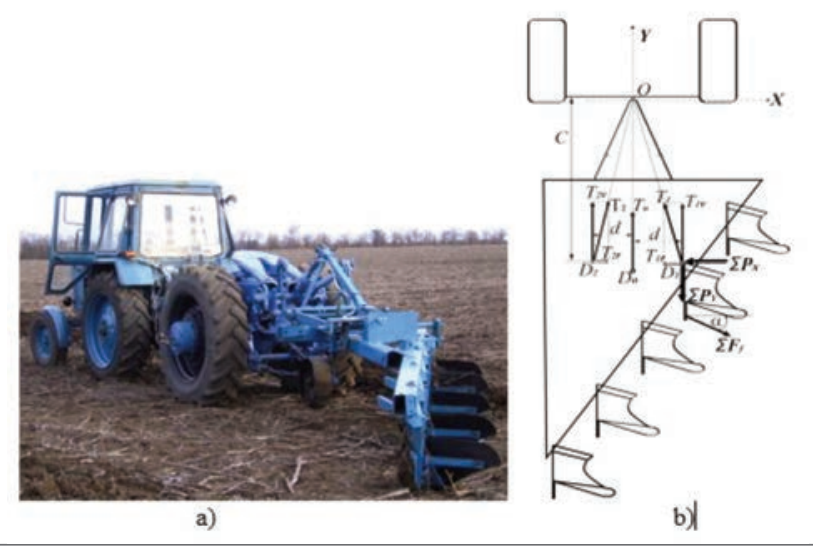

Figure 1. The modular draft device MDD-100 (A) and scheme (B) of the forces $\left(T_{1}, T_{0}, T_{2}\right)$ acting on the plough with different location options of its resistance centre (points $D_{1}, D_{0}, D_{2}$ ). 
where $f_{t r}, \varphi$ are the coefficient and angle of the soil friction against steel, respectively and $\gamma$ is the angle on the plane between the plough share blade and the furrow wall. Considering the soil conditions of southern Ukraine the average values of these parameters are as follows: $f_{t r}=0.5 ; \varphi=28^{\circ} ; \gamma=42^{\circ}$ (Nadykto, 2003).

The forces $T_{1 v}$ and $T_{1 r}$ acting upon the draft device are related due to the following condition (Figure 1B):

$$
T_{1 r} \cdot C-T_{1 v} \cdot d=0
$$

where $C$ - the arm of force $T_{1 r}$.

On the other hand, these forces can be defined as follows:

$$
\begin{aligned}
& T_{1 r}=\Sigma F_{f} \cdot \cos \alpha-\Sigma P_{x} \\
& T_{1 v}=\Sigma F_{f} \cdot \sin \alpha+\Sigma P_{Y}
\end{aligned}
$$

After substituting formulas (1) and (3) into (2) we find that

$$
\Sigma F_{t r}=\Sigma P_{Y} \cdot \frac{C \cdot \cot (\varphi+\gamma)+d}{\frac{C}{f_{t r}}-d}
$$

Now we will consider the option of placing the centre of resistance of the plough at point $D_{o}$, which is located along a plane crossing the longitudinal axis of symmetry of the tractor (Figure 1). At present, most scientists and practitioners consider this option of attaching the plough to be the best. At the same time, under real operating conditions of the ploughing unit, the position of the tractor traction force $T_{o}$ in point $D_{o}$ (Figure 1B) is not constant. The fact is that the plough is not rigidly attached to the tractor, but it is articulated on the basis of a two-point or a three-point scheme. According to the laws of mechanics, the plough is, in fact, a physical pendulum making independent angular oscillations in the soil along a horizontal plane relative to the tractor. However, the latter, in turn, during its working movement, makes its own angular oscillations along the same plane. As a result, there is always an angle between the longitudinal symmetry axes of the tractor and the

\begin{tabular}{|c|c|}
\hline MDD & Modular draft device \\
\hline EM & Energy module \\
\hline TM & Technological module \\
\hline PSL & Power saturation level, $\mathrm{kW} \mathrm{t}^{-1}$ \\
\hline $\mathrm{D}$ & Distance between plough centre of resistance and draft device symmetry longitudinal axis, $\mathrm{m}$ \\
\hline$T_{1}, T_{0}, T$ & Tractor's tractive forces, $\mathrm{kN}$ \\
\hline$T_{1 \mathrm{v},} T_{1 \mathrm{r}}$ & longitudinal and transverse components of the tractor tractive force $\mathrm{Tl}, \mathrm{kN}$ \\
\hline$T_{2 v}, T_{2 v}$ & longitudinal and transverse components of the tractor tractive force $\mathrm{T} 2, \mathrm{kN}$ \\
\hline$\Sigma F_{t r}$ & Plough landside friction force against the soil, kN \\
\hline$\Sigma P_{x}$ & Total transverse (horizontal) soil reaction, $\mathrm{kN}$ \\
\hline$\Sigma P_{Y}$ & Total longitudinal (vertical) soil reaction, $\mathrm{kN}$ \\
\hline$\Sigma F_{f}$ & Total normal reaction of the plow landsides, $\mathrm{kN}$ \\
\hline$f_{t r}$ & Coefficient of the soil friction against steel, dimensionless \\
\hline$\phi$ & Angle of the soil friction against steel, deg \\
\hline$\gamma$ & Angle in the plane between the plough share blade and the furrow wall, deg \\
\hline C & Arm of force $\mathrm{T}_{1 r}, \mathrm{~m}$ \\
\hline$B_{k}$ & Wheel track of the tractor, $m$ \\
\hline$B_{p}$ & Plough's working width, $m$ \\
\hline$A$ & Distance from the furrow wall to the edge of the tractor wheel, $\mathrm{m}$ \\
\hline B & Width of the tractor tire, $\mathrm{m}$ \\
\hline$b_{k}$ & Width of the plough bottom, $m$ \\
\hline$N$ & Number of the plough bottoms, dimensionless \\
\hline$L$ & Distance between each peg and furrow wall covered by the plowing unit during its previous passage, $\mathrm{m}$ \\
\hline$h_{i}$ & Distance from each peg to the furrow wall covered by the plowing unit during its last passage, $\mathrm{m}$ \\
\hline$\Delta$ & Skidding of the wheels, $\%$ \\
\hline$n_{x}, n_{p}$ & Wheel rotational speed respectively without and with a tractive load, rpm \\
\hline$V_{x}, V_{p}$ & Tractor travelling speed respectively with and without a tractive load, $\mathrm{m} \mathrm{s}^{-1}$ \\
\hline$t$ & Time, s \\
\hline$N_{S}$ & Total number of pulses generated by the hermetic contact sensor, dimensionless \\
\hline$t_{s}$ & Duration in time between two subsequent impulses of hermetic contact sensor, s \\
\hline
\end{tabular}
plough, having a zero value which is instantaneous (i.e., transitional) and, naturally, random.

Table 2. Abbreviations and symbols used in article. 
Now let us consider an option in which the centre of resistance of the plough is located to the left of the $O Y$ axis at a distance $d$ (point $D_{2}$, Figure 1B). In this case the tractive force of the tractor $T_{2}$ can also be decomposed into two components: longitudinal $\left(T_{2 v}\right)$ and transverse $\left(T_{2 r}\right)$. Like in the option with point $D_{1}$, the first of these forces performs useful work, as it moves the plough in the direction of the tractor movement. The second component $\left(T_{2 r}\right)$ is also efficient, because it tries to push the plough away from the furrow wall. As a result, this causes the unloading of its landside plates, therefore the force of their friction against the soil decreases.

In addition, the nature of force $\Sigma F_{t r}$ changes and becomes as follows:

$$
\Sigma F_{t r}=\Sigma P_{Y} \cdot \frac{C \cdot \cot (\varphi+\gamma)-d}{\frac{C}{f_{t r}}+d}
$$

The value of the lateral displacement of the centre of resistance of the plough $(d)$ is closely related to the pattern of the movement of the draft device with the plough.

Now two of them are known: i) the draft device moves outside the furrow; ii) the draft device moves with the one-side wheels in the furrow. Here the value of parameter $d$ is determined in the following way:

- when the draft device is moving outside the furrow:

$$
d=\left[B_{k}+2 \cdot A+b-b_{k} \cdot(n+1)\right] \cdot 2^{-1}
$$

- when the draft device is moving in the furrow:

$$
d=\left[B_{k}-b-b_{k} \cdot(n+1)\right] \cdot 2^{-1},
$$

where $B_{k}$ is the wheel track of the tractor; $A$ is the distance from the furrow wall to the edge of the tractor wheel; $b$ is the width of the tractor tire; $b_{k}, n$ is the width of the plough bottom and number, respectively.

There are many points of view regarding the choice of the value for parameter $A$. It is believed that the greater this value, the less the risk that the tractor may slide down with its right wheels into the furrow. For this reason, the value chosen for parameter $A$ is very often equal to the ploughing depth.

On the other hand, the more stable the tractor is on the horizontal plane, the smaller the value of this parameter may be. The practice of using the MDD-100 shows that its stability is ensured at $A$ $=150 \mathrm{~mm}$.

\section{Materials and methods}

\section{The properties of the modular draft device}

The physical object of our research work was a ploughing unit consisting of an MDD-100 and a mounted five-bottom plough PLN-5-35 (Figure 1A). The design parameters of the latter are as follows: width of the plough bottom $b_{k}=350 \mathrm{~mm}$; number of bodies $n=5$; working width of the plough $B_{p}=1.75 \mathrm{~m}$.

This ploughing unit was compared with another one consisting of a tractor MTZ-892 and a similar mounted three-bottom plough
(PLN-3-35). The energy saturation level of this tractor was equal to the energy saturation level of the MDD-100 energy module.

\section{Structure of the experiment}

Two patterns of the movement of the investigated ploughing units were considered under the field conditions: i) the right-side wheels of the MDD-100 were in the furrow; ii) the right-side wheels of the MDD-100 were outside the furrow. The ploughing unit, based on the MDD-892, moved according to the second pattern. The moisture and density of the soil samples were determined from a layer of $0-30 \mathrm{~cm}$. In order to determine the first of these parameters, the well-known thermostat-weighting method (standard SRPS ISO 11272:2007) was used. To determine soil density, a special densitometer was used (Nadykto and Kotov, 2015). During the research process, we measured 8 parameters: i) soil moisture; ii) soil density; iii) traction resistance of the plough $\left(R_{p}\right.$ $\left.=\Sigma P_{Y}\right)$; iv) the revolutions of the wheel of the technological module under and without the tractive load $\left(n_{x}, n_{p}\right)$; v) the width of the ploughing aggregate $\left(B_{p}\right)$; vi) the depth of ploughing; vii) fuel consumption $\left(G_{h}\right)$; viii) times the aggregate passes the test section.

The average humidity value was determined using soil samples, which were dried at $105^{\circ} \mathrm{C}$ for $3 \mathrm{~h}$ inside a forced air oven ARGOLAB model TCF 200 (Argolab-XS Instruments s.r.l. Industry, Carpi, Modena district, Italy). Soil samples were weighed before and after drying using an electronic ABT model 220-5DM analytical balance (KERN \& SOHN GmbH Industry, Balingen, Germany) with the following technical characteristics: $0.22 \mathrm{~kg}$ max. capacity and $10^{-8} \mathrm{~kg}$ readability.

The measurement of soil density was carried out as follows. Samples were taken from a given soil layer using a cylinder with a volume of $28.35 \mathrm{~cm}^{3}$ and weighed on an FC-50 (China) balance with a weighing range of 0.001-50 g. The scales were set to measure in ounces. As a result, their scale displayed the weight of the soil in ounces, whereby a sample volume of $28.35 \mathrm{~cm}^{3}$ corresponded to its density in $\mathrm{g} \mathrm{cm}^{3}$.

The strain gauge link (Ukraine) is equipped with foil strain gauges KFG-20-120-C1 (KYOWA, Japan) included in the full bridge for measuring traction resistance up to $50 \mathrm{kN}$. The strain gauge coefficient of the strain gages is 2 . The normally open hermetic contacts of the MKA-27101-B series (Ukraine) have a resistance of $0.15 \Omega$ and are designed for a current of up to $0.5 \mathrm{~A}$.

We used an L-CARD model E14-140-M (Moscow, Russian Federation) converter with the following characteristics: 32 bits processor, $48 \mathrm{MHz}$; 8 differential or 16 with common ground input channels.

In order to measure the plough width with an accuracy of $1 \mathrm{~cm}$, we used a Tolsen tape measure (China) with a measurement limit of up to $3 \mathrm{~m}$. The ploughing depth was measured with a ruler having a measuring range of $0-50 \mathrm{~cm}$ and with a measurement error of $\pm 0.5 \mathrm{~cm}$. An electronic stopwatch FS-8200 (China) was used to measure time with a measurement error of $\pm 0.1 \mathrm{~s}$.

To measure the draft resistance of the plough and the wheel revolutions of the module, a strain measuring element and a sensor with a hermetic contact sensor were used, respectively. Electrical signals from the strain-measuring element and the module wheels were transmitted to an analog-to-digital converter, and then to a computer. Furthermore, the strain-measuring element of the plough formed an analog signal, but the hermetic contact sensor formed an impulse (pulse). In order to determine the working width of the plough, before the passage of the ploughing unit, at a $2 \mathrm{~m}$ distance $L$ from the furrow wall, there were 200 pegs stuck in with a step of $1 \mathrm{~m}$. After the ploughing unit had passed, the distance $\left(h_{i}\right)$ from each peg to the wall of the newly created furrow 
was measured.

The working width of the plough $\left(B_{p}\right)$ was determined on the basis of the following expression:

$B_{p}=L-h_{i}$

The strain measuring plough was set to a ploughing depth of $25 \mathrm{~cm}$. The number of measurements of this parameter after every $20 \mathrm{~cm}$ was 100 .

Fuel consumption of the ploughing unit was measured using a flow meter DFM 100 DK (Minsk, Belarus) with a measurement error of no more than $1 \%$.

To calculate the skidding of the MDD-100 wheels, the following formula was used:

$$
\delta=1-\frac{n_{x} \cdot V_{p}}{n_{p} \cdot V_{x}},
$$

where $V_{x}, V_{p}$ stood for the speed of the movement of the MDD-100 with and without a tractive load, respectively; $n_{x}, n_{p}$ were the revolutions of the TM wheels when driving the MDD-100 without a tractive load and with it, respectively.

The speed of the movement of the ploughing unit $V_{x}, V_{p}\left[\mathrm{~m} \cdot \mathrm{s}^{-1}\right]$ was calculated according to the following formula:

$$
\underline{V_{p}}\left(V_{x}\right)=250 \cdot t^{-1} V_{p}\left(V_{x}\right)=250 \mathrm{~m} \cdot t^{-1}
$$

where $t$ was the duration of the $250 \mathrm{~m}$-long test plot covered by ploughing unit.

The wheel revolutions of the technological module $\left(n_{x}, n_{p}\right)$ were determined as follows:

$$
n_{p}\left(n_{x}\right)=\left(N_{s}-1\right) \cdot\left(2 t_{s}\right)^{-1}
$$

where $N_{S}$ was the total number of pulses generated by the hermetic contact sensor; $t_{S}$ was the timeframe between two subsequent impulses of hermetic contact sensor, s.

To estimate the internal nature of fluctuations in the depth and width of the arable land, as well as the draft resistance of the plough, normalized correlation functions and spectral densities of these processes were applied.

\section{Results and discussion}

Let us consider the impact of parameter $d$ on the nature of the change in the friction force $\Sigma F_{t r}$ (Figure 1B). The analysis of equa- tion (4) shows that the growth of this unproductive force is due to the increase in the value of the right-side lateral displacement of the centre of resistance of the plough (Figure 2, line 1).

The expression (4) was calculated on the basis of the following values: $B_{p}=\Sigma P_{Y}=30 \mathrm{kN}$ (this parameter, like all the following ones, is typical for the PLN-5-35 plough and the soil conditions in the south of Ukraine); $C=2.55 \mathrm{~m} ; \varphi=28^{\circ} ; \gamma=42^{\circ} ; f_{t r}=0.5$.

On the contrary, the analysis of formula (5) shows that a decrease in the unproductive friction force $\Sigma F_{t r}$ occurs when there is a left-side transverse displacement of the coordinate of the centre of resistance of the plough (Figure 2, line 2). At the same time, at a certain displacement value $d$, force $T_{2 r}$ can increase to such an extent that it may cause the plough to lose stability on a horizontal plane. As shown by the analysis of equation (5), this result can be avoided if the following condition is met:

$$
d \cdot C \cdot \cot (\varphi+\gamma) \cdot d \leq C \cdot \cot (\varphi+\gamma) .
$$

In this case, the value of the friction force $\Sigma F_{t r}$ will be greater than zero, and the plough will remain stable on the horizontal plane.

Calculations based on formulas (6) and (7) give the following result. When the MDD-100 moves outside the furrow, the centre of resistance of the plough is located to the right of the longitudinal axis of the traction means at distance $d=0.065 \mathrm{~m}$. On the contrary, when the MDD-100 moves in the furrow, the centre of resistance of the plough is located to the left of the longitudinal axis of symmetry of the traction means at distance $d=0.515 \mathrm{~m}$. The working conditions of the soil for the ploughing unit are shown in Table 3.

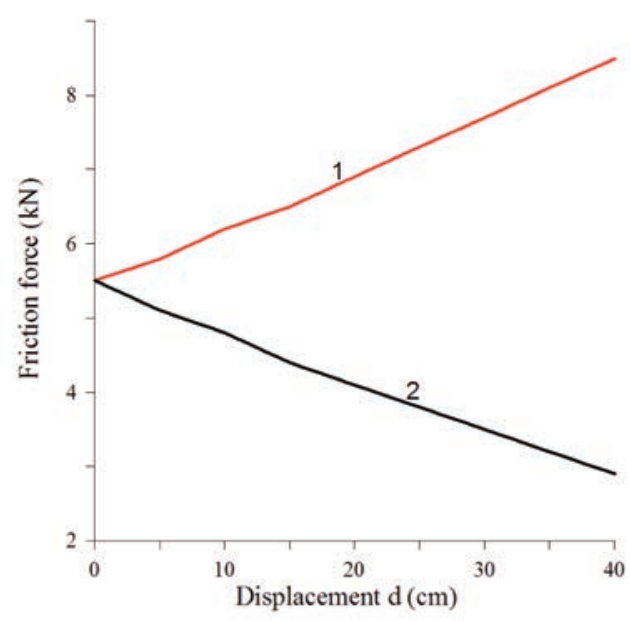

Figure 2. Impact of parameter $d$ on the friction force $\Sigma F_{t r}$ during the right-side (1) and the left-side (2) transverse displacement of the resistance centre of the plough.

Table 3. Field soil characteristics.

\begin{tabular}{lcl} 
Parameter & Unit & Value \\
Soil type & & Dark-chestnut black soil: humus - 4...5\%, clay - >50\%, sand - 5...6\%, silt - less than $1.5 \%$ \\
Agrotechnical background & \multicolumn{1}{c}{$\begin{array}{l}\text { Sunflower stubble } \\
\text { Soil moisture in a layer } 0-30 \mathrm{~cm}\end{array}$} & $18-20$ \\
Soil density in a layer $0-30$ & $\mathrm{~g} \mathrm{~cm}^{-3}$ & $1.18-1.20$ \\
\hline
\end{tabular}


During the test, the MDD-100 moved in the furrow and out of it in the same gear. The analysis of the obtained data revealed that the difference between the average values of the working width of the compared variants of the ploughing unit was $0.01 \mathrm{~m}$ (Table 4). This is considerably less than the smallest significant difference $\left(L S D_{05}\right)$, which is $0.03 \mathrm{~m}$ with respect to the statistical significance level of 0.05 . Therefore, the null hypothesis about the equality of the compared average ploughing depths is not rejected, because both processes of fluctuations in the working width of the plough are statistically similar.

The same can be said about the dispersions (variances) of the compared processes. In addition, the actual value of the Fisher Ftest is equal to $F_{r}=4.40 / 4.10=1.10$, but the tabular value is $F_{t}=$ 1.26. Since in this case $F_{r}<F_{t}$, the difference between the dispersions (variances) of the compared processes $\left(4.40 \mathrm{~cm}^{2}\right.$ and 4.10 $\mathrm{cm}^{2}$, Table 4), is not essential.

Moreover, the compared dispersions (variances) are approximately equally distributed by frequencies. More precisely, the normalized spectral densities of the working width fluctuations of both variants of the ploughing unit indicate (Figure 3) that the maximum dispersion values refer approximately to the same frequency of $0.75 \mathrm{~s}^{-1}(0.12 \mathrm{~Hz})$. Furthermore, the main spectrum of dispersions is concentrated in a very narrow frequency range: $0 \ldots .4 \mathrm{~s}^{-1}$ or $0 \ldots .0 .6 \mathrm{~Hz}$. This means that fluctuations in the working width of the plough in the ploughing unit, based on the MDD100 , have a low frequency irrespective of whether it moves in the furrow or outside it. As noted above, when the MDD-100 moves in the furrow, the centre of resistance of the plough shifts to the left of the longitudinal axis of the traction tool by $0.515 \mathrm{~m}$. According to equation (5) and the data of Figure 2, this should lead to a decrease in the draft resistance of the plough.

Experimental investigations have fully confirmed the results of the theoretical calculations. When the MDD-100 moved in the furrow, the draft resistance of the PLN-5-35 plough was $3.26 \mathrm{kN}$ lower (Table 4). This difference is statistically significant, because it is much larger than $L S D_{05}=0.30 \mathrm{kN}$. The other statistical char-

Table 4. Results of the field studies of the ploughing units.

\begin{tabular}{|c|c|c|}
\hline Indicator & $\begin{array}{l}\text { MDD-100 } \\
\text { in the } \\
\text { furrow }\end{array}$ & $\begin{array}{l}\text { MDD-100 } \\
\text { outside } \\
\text { the furrow }\end{array}$ \\
\hline Working speed $\left(\mathrm{m} \cdot \mathrm{s}^{-1}\right)$ & 2.2 & 2.0 \\
\hline $\begin{array}{l}\text { Ploughing width: } \\
\text { Average }(\mathrm{cm}) \\
\text { Variance }\left(\mathrm{cm}^{2}\right) \\
\text { Coefficient of variation }(\%) \\
\text { Least significant difference }(\mathrm{cm})\end{array}$ & $\begin{array}{c}177 \pm 2 \\
4.10 \\
1.11 \\
3\end{array}$ & $\begin{array}{c}178 \pm 2 \\
4.40 \\
1.18\end{array}$ \\
\hline $\begin{array}{l}\text { Ploughing depth: } \\
\text { Average }(\mathrm{cm}) \\
\text { Variance }\left(\mathrm{cm}^{2}\right) \\
\text { Coefficient of variation }(\%) \\
\text { Least significant difference }(\mathrm{cm})\end{array}$ & $\begin{array}{c}24.88 \pm 0.18 \\
0.80 \\
3.6 \\
0.28\end{array}$ & $\begin{array}{c}25.06 \pm 0.20 \\
1.00 \\
4.1\end{array}$ \\
\hline $\begin{array}{l}\text { Draft resistance of the plough: } \\
\text { Average }(\mathrm{kN}) \\
\text { Variance }\left(\mathrm{kN}^{2}\right) \\
\text { Coefficient of variation }(\%) \\
\text { Least significant difference }\left(L S D_{05}, \mathrm{kN}\right)\end{array}$ & $\begin{array}{c}24.09 \pm 0.21 \\
1.10 \\
4.3 \\
0.30\end{array}$ & $\begin{array}{c}27.35 \pm 0.20 \\
1.00 \\
3.7\end{array}$ \\
\hline Skidding (\%) & 11.6 & 13.3 \\
\hline Fuel consumption per tilled area $\left(\mathrm{FCA}, \mathrm{L} \cdot \mathrm{ha}^{-1}\right)$ & 1) 15.2 & 17.5 \\
\hline
\end{tabular}

acteristics of fluctuations in the draft resistance of the plough are practically the same for both variants of the attachment to the MDD-100. Namely, the maximum spectral density of the fluctuations in the draft resistance of the plough refer to approximately the same frequency $2.5 \mathrm{~s}^{-1}$ or $0.4 \mathrm{~Hz}$ (Figure 4).

Almost the entire dispersion spectrum of fluctuations in the draft resistance of the plough is concentrated in the frequency range $0 \ldots .25 \mathrm{~s}^{-1}$ (i.e., $0 \ldots 4 \mathrm{~Hz}$ ), which is typical in most ploughing units (Lur'e, 1970). A lower draft resistance of the plough during the movement of the MDD-100 in the furrow made it possible to reduce wheel skidding by $12.8 \%$, and its specific (per hectare) fuel consumption by $13.1 \%$ (Table 4 ). When estimating the depth of ploughing, the following results were obtained. When the MDD100 moved outside the furrow, the average value of this parameter was by $0.18 \mathrm{~cm}$ less than when it moved in the furrow (Table 3 ). However, this difference is less: $L S D_{05}=0.28 \mathrm{~cm}$. Hence, the null hypothesis about the equality of the compared average values of the ploughing depth is not rejected. The actual value of the $F$-Fisher criterion for the compared dispersions (variances) of the ploughing

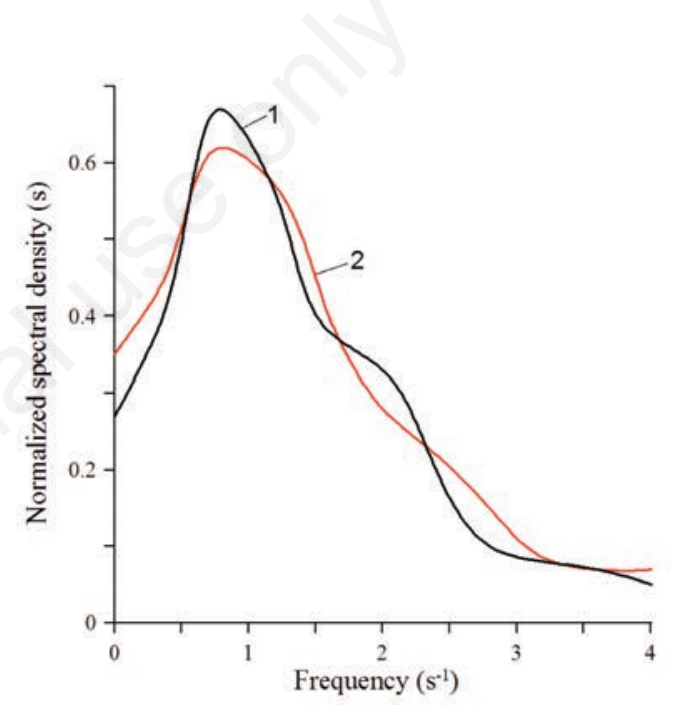

Figure 3. Normalized spectral densities of fluctuations in the ploughing widths, when the MDD-100 moves in the furrow (1) and outside it (2).

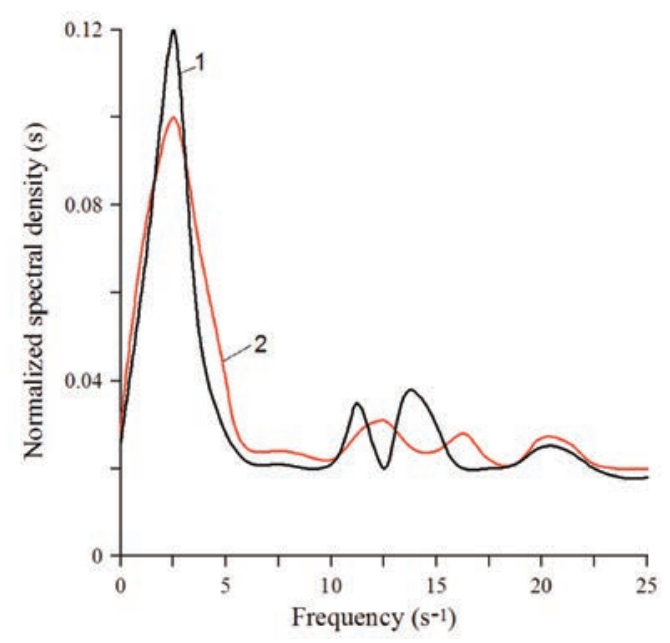

Figure 4. Normalized spectral densities of the plough draft resistance fluctuations, when the MDD-100 moves in the furrow (1) and outside it (2). 
depth fluctuations is 1.25 . This is less than the tabular value of the FFisher criterion, equal to 1.26. Therefore, the difference between the compared dispersions (variances) $\left(0.80 \mathrm{~cm}^{2}\right.$ and $\left.1.00 \mathrm{~cm}^{2}\right)$ is random and not essential. Moreover, the internal structure of fluctuations in the ploughing depth of both versions of the ploughing unit is approximately the same. This conclusion follows from the analysis of the normalized correlation functions of these processes. It should also be noted that the points in which these functions ( 1 and 2, Figure 5 ) cross the zero mark determine the length of the correlation. As can be seen, this length is approximately the same for both variants of the MDD movement with the plough, i.e. 3.7 and $3.8 \mathrm{~m}$. In addition, the ploughing depth oscillations do not have an explicit periodic component. Now, we analyse the results obtained for the ploughing unit based on the MTZ-892 tractor. The average ploughing depth varied within a range of $24.64 \pm 0.24 \mathrm{~cm}$, which is practically the same as the one obtained for the ploughing unit based on the MDD-100.

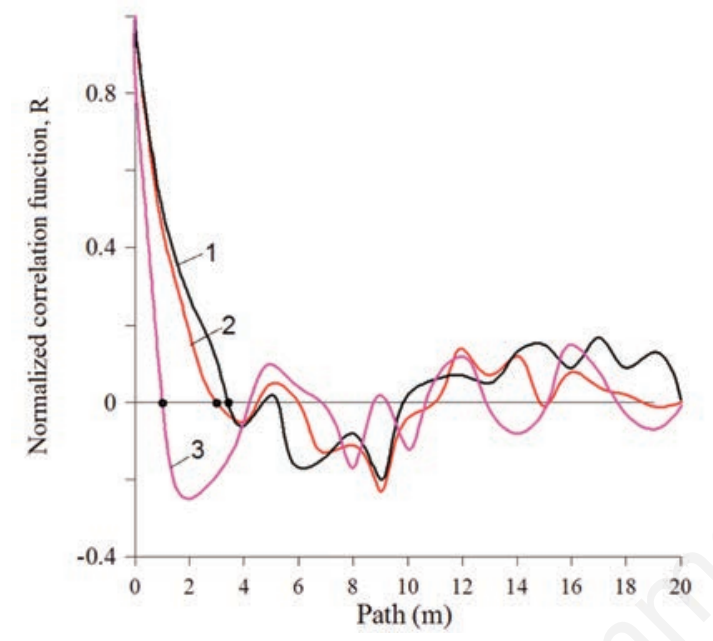

Figure 5. Normalized correlation functions of the ploughing depth fluctuations: 1 - the MDD-100 in the furrow; 2 - the MDD-100 outside the furrow; 3 - the MTZ-892-based ploughing unit.

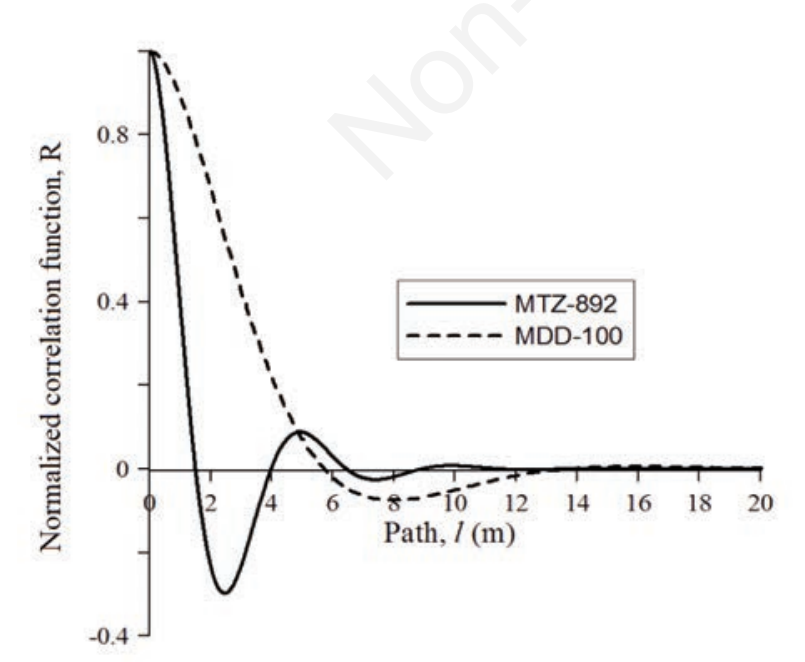

Figure 6. Normalized correlation functions of the ploughing depth fluctuations: i) for the MDD-100-based ploughing unit $\boldsymbol{R}$ $=\exp \cdot(-0.492 \cdot l) \cdot[\cos (1.275 \cdot l)+0.386 \cdot \sin (1.275 \cdot l)]$; ii) for the MTZ-892-based ploughing unit: $R=\exp \cdot(-0.325 \cdot L) \cdot[\cos (0.395 \cdot l)$ $+0.822 \cdot \sin (0.395 \cdot l)]$.
Let us analyse the variance of the ploughing depth fluctuations. The ploughing unit based on the MTZ-892 turns out to be equal to $1.47 \mathrm{~cm}^{2}$. First, we compare it with the dispersion obtained for a unit based on the MDD-100, when moving outside the furrow $\left(1.00 \mathrm{~cm}^{2}\right)$. The actual value of the F-Fisher criterion in this case is equal to $F_{r}=$ $1.47 / 1.00=1.47$, but the tabular value is $F_{t}=1.26$. As we can see $F_{r}$ $>F_{t}$. When comparing the ploughing units based on the MTZ-892 and the MDD-100, the latter moving outside the furrow, the ratio appears to be the same, since in this case $F_{r}=1.47 / 0.80=1.84$, which is much greater than $F_{t}=1.26$. As a result, we can come to the very important conclusion that the dispersion of fluctuations in the ploughing depth for units based on the MDD-100 modular traction devices is significantly lower than for a ploughing unit based on a conventional 4WD tractor. Moreover, the fluctuation frequency of this parameter of the units based on the MDD-100 was also essentially lower. As follows from the analysis of Figure 5 (function 3), the length of the correlation link of the correlation function, which characterizes the fluctuations in the depth of the ploughing unit based on the MTZ-892 tractor is approximately $1 \mathrm{~m}$. This is 3.7 and 3.8 times higher than that of the ploughing units based on the MDD-100 (functions 1 and 2, Figure 5). However, in theory it is known that the shorter the length of the correlation link of the correlation function, the higher the frequency of the process fluctuations (Lur'e, 1970). The difference between the fluctuation frequencies in the ploughing depth of the compared ploughing units is more obvious when their normalized correlation functions are compared (Figure 5) approximated by the corresponding analytical dependences (Figure 6). Figure 6 shows that the length of the correlation link between the values of the ploughing depth of a unit based on the MTZ-892 tractor is almost three times shorter than that of the ploughing unit based on the MDD100. In principle, this can enable us to argue that the fluctuations in the ploughing depth of the unit based on a conventional two-axle tractor are higher than those of a ploughing unit, based on a three-axle modular traction device. To explain this result, let us analyse the structural schemes of the ploughing units from the longitudinal vertical plane (Figure 7). This analysis covers the following: the

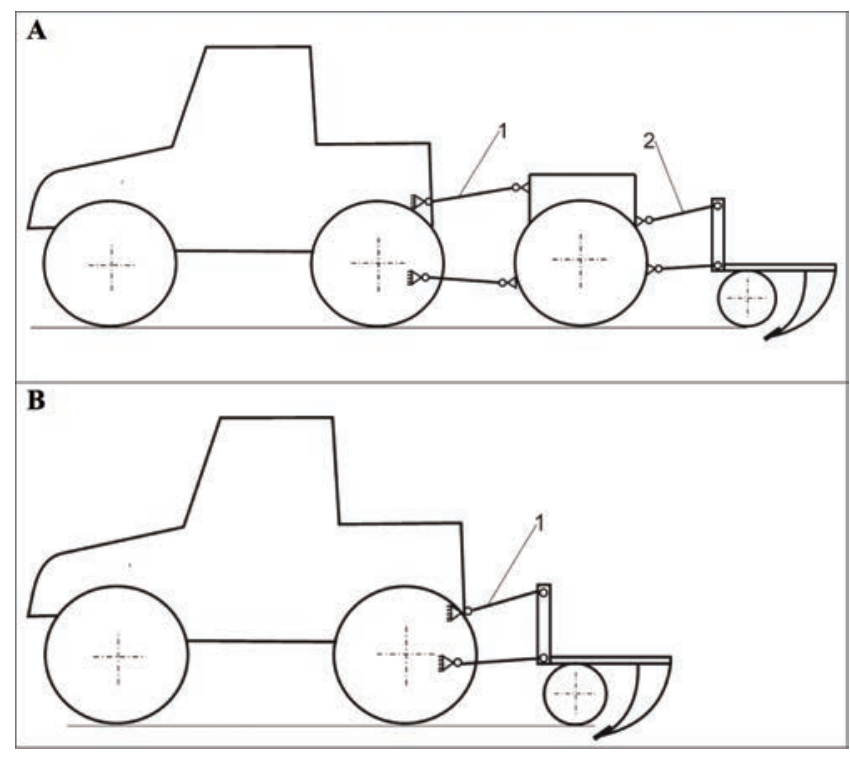

Figure 7. Structural schemes of the (A) MDD-100-based and the (B) MTZ-892-based ploughing units: 1 - the energy module and a three-point hitch linkage (TPHL) of the tractor; 2 - the TPHL of the technological module. 
ploughing unit based on the MDD-100 is represented by the following structural chain (Figure 7A): «EM - EM's TPHL - TM TM's TPHL - Plough». The structural scheme of a ploughing unit based on the MTZ-892 is shorter (Figure 7B): «Tractor - Tractor TPHL - Plough».

This allows us to suppose that the unit based on a modular traction device has a longer and more flexible structural chain and reflects better the longitudinal profile of the field. Due to the TM, the longitudinal-vertical vibrations of the EM affect significantly less the longitudinal-vertical vibrations of the plough. As a result, its movement on this plane is more stable, hence the ploughing depth is more stable too.

\section{Conclusions}

The above analysis shows that placing the plough centre of resistance on a plane crossing the longitudinal axis of the tractor symmetry is not an optimal decision. The best choice for using the MDD-100 modular traction device with a plough is its movement with the [one-side] wheels in the furrow. In comparison with the MDD-100 variant with the movement outside the furrow, the draft resistance of the plough is reduced by $12.0 \%$. Skidding of the modular traction device is $12.8 \%$ less, while its specific (per hectare) fuel consumption - is $13.1 \%$ lower.

The movement of the ploughing unit based on the MDD-100 with the right-side wheels in the furrow causes lesser dispersion $\left(4.00 \mathrm{~cm}^{2}\right)$ and a lower (no more than $0.6 \mathrm{~Hz}$ ) fluctuation frequency of the working width of the plough. Compared to the 4WD tractor, the use of a modular traction 6WD device in the unit with a plough offers fewer fluctuations in the depth of ploughing, both in amplitude and in frequency.

\section{References}

Beloousov B., Ksenevich T.I., Vantsevich V., Komissarov D. 2013. $8 \times 8$ Platform for studing terrain mobility and traction performance of unmanned articulated ground vehicles with steered wheels. SAE Techn. Paper Series 1-17. Available from: https://doi.org/10.4271/2013-01-2356

Bulgakov V., Kyurchev V., Nadykto V., Beloev H., Mitev G. 2016. Development of structures and results of experimental studies of the new modular power unit. Mech. Agric. 3:25-9.

Bulgakov V., Kyurchev V., Nadykto V., Olt J. 2015. Structure development and results of testing a novel modular power unit. Agric. Agric. Sci. Procedia 7:40-4.

Kutkov G. 2004. Tractors and automobiles. Theory and technological properties. Kolos, Moscow, Russia [in Russian].

Lur'e A. 1970. Statistical dynamics of agricultural sets. Kolos, Moscow, Russia [in Russian].

Nadykto V. 2003. The foundations of modular energetic devices applying. Melitopol: KP "MMD” [in Russian].

Nadykto V., Kotov O. 2015. Method for determining soil bulk density (Sposib viznachennya shchilnosti gruntu). Patent of Ukraine UA 97828, G 01N 1/00. [in Ukrainian].

Pădureanu V., Lupu M.I., Canja C.M. 2013. Theoretical research to improve traction performance of wheeled tractors by using a supplementary driven axle. Comput. Mechan. Virtual Engine. Braşov, Romania, 410-5.

Simikić M., Dedović N., Savin L., Tomić M., Ponjičan O. 2014. Power delivery efficiency of a wheeled tractor at oblique drawbar force. Soil Tillage Res. 141:32-43.

Simikić M., Dedović N., Savin L., Tomić M., Silleli H.H., Ponjičan O. 2012. Influence of eccentric drawbar force on power delivery efficiency of a wheeled tractor. Turkish J. Agric. Forest. 36:486-500.

Stjelja Z. 2002. Utilization quality of rubber belted tractors with reference to the improvement of tractive performance. University of Novi Sad, Faculty of Agriculture. 